\title{
The gut microbiome in cardio-metabolic health
}

\author{
Tue H Hansen ${ }^{1}$, Rikke J Gøbel ${ }^{1}$, Torben Hansen ${ }^{1,2}$ and Oluf Pedersen ${ }^{1 *}$
}

\begin{abstract}
With the prevalence of cardio-metabolic disorders reaching pandemic proportions, the search for modifiable causative factors has intensified. One such potential factor is the vast microbial community inhabiting the human gastrointestinal tract, the gut microbiota. For the past decade evidence has accumulated showing the association of distinct changes in gut microbiota composition and function with obesity, type 2 diabetes and cardiovascular disease. Although causality in humans and the pathophysiological mechanisms involved have yet to be decisively established, several studies have demonstrated that the gut microbiota, as an environmental factor influencing the metabolic state of the host, is readily modifiable through a variety of interventions. In this review we provide an overview of the development of the gut microbiome and its compositional and functional changes in relation to cardio-metabolic disorders, and give an update on recent progress in how this could be exploited in microbiota-based therapeutics.
\end{abstract}

\section{Introduction}

The dramatic increase in the prevalence of obesity worldwide [1,2] is associated with serious health risks, including increased susceptibility to co-morbidities such as type 2 diabetes (T2D) and cardiovascular disease (CVD). Both genetic susceptibility and environmental factors (such as intrauterine conditions, physical inactivity, smoking and unhealthy dietary habits) are involved in the pathogenesis of cardio-metabolic disorders [3,4]. Recent findings suggest that the environmental component in the development of metabolic dysfunction is mediated, at least in part, through an altered gut microbial

\footnotetext{
* Correspondence: oluf@sund.ku.dk

${ }^{1} T$ The Novo Nordisk Foundation Center for Basic Metabolic Research, Section of Metabolic Genetics, Faculty of Health and Medical Sciences, University of Copenhagen, Universitetsparken 1, København $\varnothing$ 2100, Denmark Full list of author information is available at the end of the article
}

structure and function. The gut microbiota maintains several essential functions, including colonic fermentation of dietary fibers; extraction of nutrients; synthesis of certain vitamins; prevention against colonization by pathogens; maturation of the intestinal epithelium and immune system; release of metabolites to the systemic tissues; and modulation of gastrointestinal hormone release and nerve function [5-8]. It is thus increasingly recognized that the configuration and activity of the gut microbiota, influenced by host genotype and additional environmental factors, affect host biology in numerous ways.

Recent studies in animal models and humans have found correlations between specific alterations in the gut microbiota community structure and the onset of diabetes, obesity and CVD. There is evidence for the influence of diet on the gut microbiota in various diseases, and several microbial metabolites have been shown to have a significant effect on the metabolic health of the host through pathways that influence intestinal health, such as mucosal permeability, inflammation and immune function [9-11]. Lifestylerelated shifts in the bacterial composition and function can break the delicate balance of the microbial composition and lead to a state of chronic disequilibrium referred to as dysbiosis, a condition that has been associated with several pathologies, including obesity and T2D [12-17].

In this review, we examine what current technologies have taught us about the origins and composition of the gut microbiome, and how this is associated with cardiometabolic disease. We consider recent studies that provide insights into the role of the human gut microbiota in the metabolic health spectrum, and discuss how this relationship can be exploited and modulated to improve health.

\section{Gut microbiota composition}

Culture-independent methods are now being used to analyze microbial ecosystems, combining high-throughput sequencing of nucleic acids (DNA, RNA) with advanced bioinformatics for taxonomic mapping. Before these 
approaches, only those microbes that could be cultured were characterized, comprising about $20 \%$ of the total [18]. Because the majority of intestinal bacterial species are anaerobic and difficult to cultivate, gene-based studies have now been developed to study the broad spectrum of both anaerobic and aerobic gut bacteria. These technologies include targeted rRNA gene markers such as 16S rRNA gene sequencing, which focus on microbial composition and diversity, and untargeted shotgun sequencing, which in addition enables assessment of the functional capability of the gut microbiota (Box 1 and Figure 1) [19].
As a result of the application of these technologies, much has been learned about the origins and composition of the human microbiome in the past 10 years. Although the human gut is not entirely sterile in utero $[27,28]$, the extensive colonization of the gastrointestinal tract begins at birth through the transfer of bacteria from the vagina, anus and skin of the mother. In this way the newborn gut is colonized by facultative anaerobic bacteria, such as Enterobacteriaceae, streptococci and staphylococci, and these bacterial communities are highly variable in the early stage [29]. The specific bacterial pattern differs in children delivered vaginally or by

\section{Box 1: Gut microbiota research methodologies}

\section{S rRNA-based profiling}

$16 \mathrm{~S}$ rRNA gene profiling involves targeted amplification and subsequent next-generation sequencing of phylogenetically informative marker sequences of microbial DNA [20]. The taxonomic level of information varies according to the subsequent applied technology: denaturing gradient gel electrophoresis (DGGE), temperature gradient gel electrophoresis (TGGE) and terminal restriction fragment length polymorphism (T-RFLP) give poor taxonomic information, whereas phylogenic microarrays (such as HitChip), 454 pyrosequencing and Illumina MiSeq/HiSeq platforms provide quantitative information and extended taxonomic identification [21,22].

From $16 \mathrm{~S}$ rRNA data the number of different taxa present in a sample and their relative abundance can be estimated by comparisons with reference-sequence databases or by using software packages to cluster highly similar sequences into OTUs [21]. Thus, targeted 16S rRNA sequencing can describe the bacterial community in terms of which taxa or OTUs are present, their relative abundance, and their phylogenetic relationships [22]. In the literature on $16 \mathrm{~S}$ rRNA-derived taxa the term phylotype is often used instead of species, as this method of taxonomic classification is not based on phenotypic characteristics of the microbe but on phylogenetic analysis of $16 \mathrm{~S}$ rRNA sequences. About 3 million aligned and annotated 16S rRNA sequences are currently available as part of the Ribosomal Database Project [23].

\section{Shotgun sequencing (quantitative metagenomics)}

In contrast to the targeted $16 \mathrm{~S}$ rRNA approach, the untargeted metagenomics approach involves direct next-generation sequencing of community DNA without amplification of specific regions. By in-depth sequencing the whole genomic content of the gut microbiota rather than marker genes alone, a less biased and higher-resolution view of the bacterial composition can be acquired through comparison with bacterial reference genomes and microbial gene catalogs [24] or through de novo assembly [25]. In addition, information can be gained about additional elements of the microbial community, including fungi and viruses. The 2014 metagenomic catalog of the human gut microbiome (consisting of 1,267 individual metagenomes compiled from the Metagenomics of the Human Intestinal Tract (MetaHIT) consortium, Chinese and Human Microbiome Project studies) includes up to 9.9 million non-redundant genes [26]. In addition to benefits in terms of improved taxonomic description, shotgun metagenomic sequencing enables a more detailed assessment of the functional potential of the microbial community through comparison with databases of metabolic pathways (such as the Kyoto Encyclopedia of Genes and Genomes) [21]. The overwhelming amount of shotgun sequencing-based metagenomics data requires a continued development and improvement of bioinformatics tools to enhance the analysis and understanding of the complexity of the human gut microbiome. This need is clearly illustrated by the fact that currently only a minority of the gut microbial genes can be annotated to known genomes of cultured microbes. Therefore, advanced bioinformatics methods based on co-abundance have been developed to enable grouping of microbial genes into 741 large MetaGenomic Units (MGUs) representing as-yet uncultured bacterial species. Characteristically, each MGU contains more than 700 microbial genes [25]. An example of a quantitative metagenomics pipeline is given in Figure 1. 


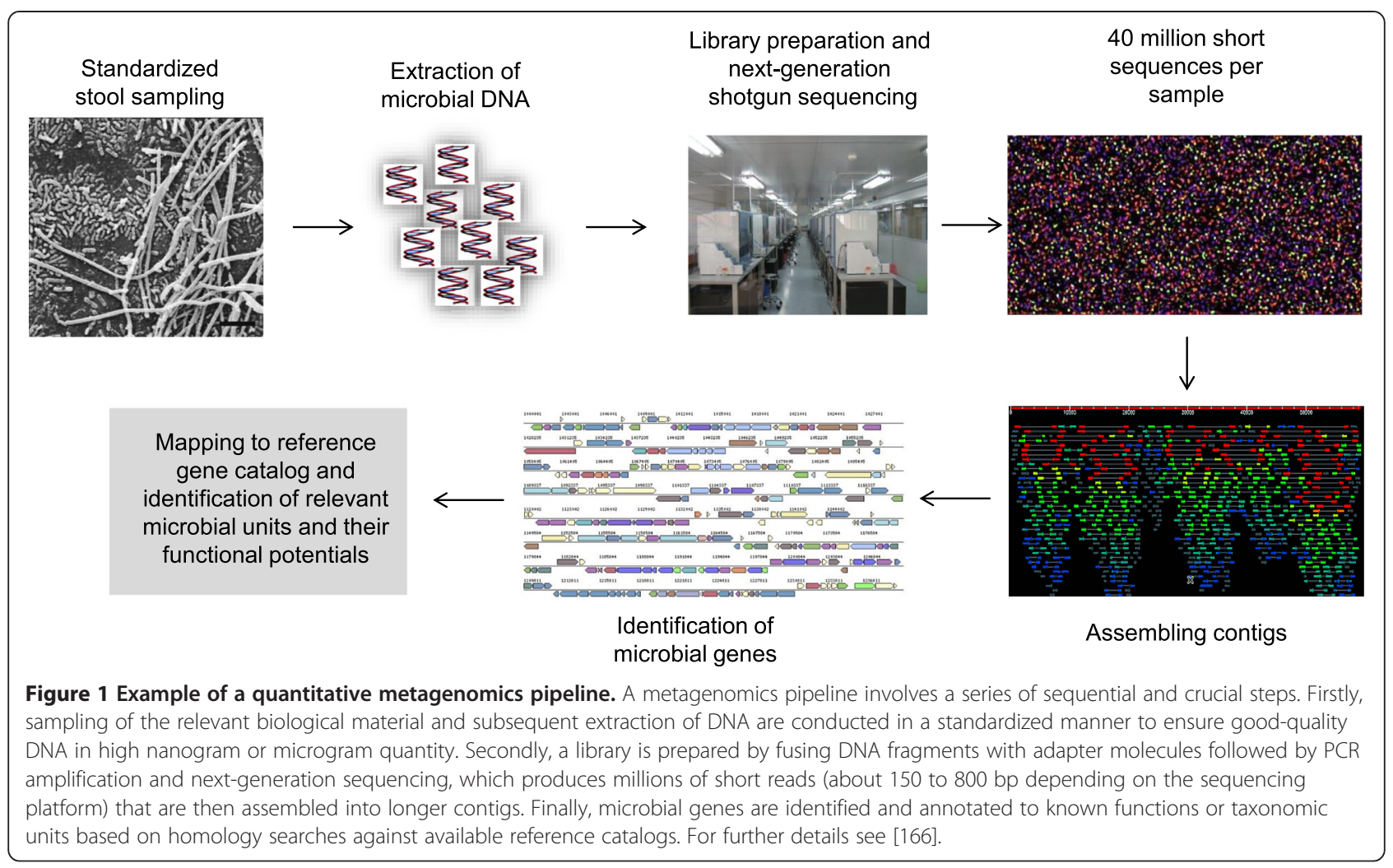

Cesarean section, with the latter affecting microbiota composition in both infancy [30] and childhood [31] and being associated with a reduced bacterial diversity [32]. This offers a potential explanation for the increased risk of atopic disorders [33] and obesity [34] observed in children delivered by Cesarean section. In addition, the gut colonization pattern differs between full-term and preterm infants [35]. The immature preterm gut along with prolonged admission at neonatal care units and the possible use of broad spectrum antibiotics delay the establishment of a beneficial bacterial community and enable the growth of potentially pathogenic bacteria [35].

Besides mode of delivery and gestational age, neonatal diet is a determining factor, and Escherichia coli and streptococci are the first bacteria to appear in newborn breast-fed infants, followed by bifidobacteria, which quickly become predominant. The microbiota of formulafed infants shows even higher variability and diversity, having lower counts of bifidobacteria and higher counts of clostridia and enterococci [29]. Weaning and the transition to solid foods confers a compositional change towards a more adult-like microbiota dominated by Clostridium spp. and Bacteroides spp. [36], with a stable adult-like microbiota, often referred to as 'the core microbiome' [37], being established at approximately the age of 3 years [38]. Most bacterial species in the adult human gut belong to the phyla Firmicutes (about 60\%), Bacteroidetes (about 15\%) and Actinobacteria (about 15\%), but less abundant microbial phyla, such as Verrucomicrobia (about 2\%), Proteobacteria (about 1\%) and Methanobacteriales (archaea) (about 1\%), are also represented [24,39-41]. Despite the phylum-level similarities, the species-level composition is highly variable between individuals, caused by environmental influence and genetic predisposition $[42,43]$. Contrary to the high interindividual variation $[44,45]$, with up to 2,187 -fold variability of microbial abundance at the species level [24], the structure of the gut microbiota of an individual remains relatively stable over time in the absence of perturbation $[46,47]$, until advanced age when the microbiota becomes less diverse and more unstable, probably related to alteration in immune competencies [48].

\section{The association of gut microbiota with cardio-metabolic disorders}

The prevalence of cardio-metabolic disorders (obesity, T2D and CVD) is increasing globally and has for several years been the number one cause of death worldwide [49]. Within the past decade the role of the gut microbiota in metabolic disorders has been extensively investigated (Table 1), and accumulating evidence indicates that a state of bacterial dysbiosis contributes to differences in body weight, insulin sensitivity, glucose metabolism and other cardio-metabolic risk factors among 
Table 1 Human metagenomic studies of the gut microbiome and cardio-metabolic traits

Aim $\quad$ Number of participants
\begin{tabular}{ll}
\hline Ley et al. (2006) [41] & $\begin{array}{l}\text { To investigate the effect of either a } \\
\text { carbohydrate- or fat-restricted diet }\end{array}$
\end{tabular} on gut microbial ecology

14 adults; 12 obese, 2 lean

Zhang et al. (2009) [161]

To investigate microbiota composition in morbid obesity and following RYGB

Turnbaugh et al. (2009) [37] To investigate the influence of hos genotype, environmental exposure and host adiposity

Larsen et al. (2010) [12]

To investigate differences in gut microbiota composition associated with T2D adults. 3 lean, 3 morbidly obese, 3 post RYGB

54 adults; $31 \mathrm{MZ}$ twin pairs, 23 DZ twin pairs, (concordant for obesity or leanness),

46 mothers
20 adults; 10 T2D, 10 NGT

Cross-sectional

165 rRNA, qPCR
165 rRNA, qPCR

Cross-sectional

Cross-sectional

165 rRNA

(1)

Jumpertz et al. (2011) [5] To investigate the effect of caloric

21 adults; 12 lean, 9 obese

Randomized cross-over

165 rRNA in lean and obese

\section{Main findings}

- Increased abundance of Firmicutes and

reduced abundance of Bacteroidetes

in obese

- Increased abundance of Bacteroidetes and decreased abundance of Firmicutes following 1 year of either fat- or

carbohydrate-restricted low-calorie diet

- Increase in Bacteroidetes correlated with body weight reduction regardless of diet

- Firmicutes dominant in normal weight and obese, decreased in post RYGB

- Gamma-Proteobacteria increased whereas Clostridia decreased post-RYGB

- Prevotellaceae highly enriched in obese

- Methanobacteriales highly abundant in obese, while non-detectable in normal weight

- Lower proportion of Bacteroidetes and a higher proportion of Actinobacteria

in obese

- Obesity associated with reduced diversity - Obese microbiome enriched for genes involved in macronutrient metabolism

- Decreased diversity in T2D

- Firmicutes, including Clostridia, decreased in $\mathrm{T} 2 \mathrm{D}$

- The ratio of the phylogenetic groups Bacteroides-Prevotella to Clostridium coccoides-Eubacterium rectale and the Bacteroidetes to Firmicutes ratio

correlated positively with $2 \mathrm{~h}$

p-glucose during an OGTT

- Beta-Proteobacteria highly enriched in T2D and correlated with 2 hour

p-glucose during an OGTT

- High-calorie diet changes the relative abundance of microbiota on the phylum (Bacteroidetes versus Firmicutes), class

(Bacteroidetes versus Clostridia), and

order level (Bacteroidales versus

Clostridiales) 


\section{Koren et al. (2011) [59] \\ To investigate the bacterial diversity of atherosclerotic plaque, oral cavity and gut in patients with CVD}

Karlsson et al. (2012) [60] To investigate the microbiota composition in patients with CVD

\section{0 adults; 15 CVD, 15 healthy Cross-sectional}

25 adults; 13 CVD, 12 healthy controls

\section{8 adults; 183 T2D cases,}

185 healthy controls

investigate differences in associated with T2D
Le Chatelier et al. (2013) [55] To investigate the bacterial abundance in lean and obese

292 adults; 123 lean, 169 obese Cross-sectional/ retrospective

Karlsson et al. (2013) [16]
Cross-sectional
To investigate differences in gut microbiota composition and function associated with T2D
145 adults; 53 T2D, 49 IGT, 43 NG

- Phylum-, class-, and order-level changes in microbiota composition during

intervention associated with fecal caloric content in lean but not in obese

165 rRNA, GPCR • No phylum- or genus level compositional difference between CVD patients and healthy controls

- Several shared OTUs between atherosclerotic plaque and fecal samples

Quantitative metagenomics · Colinsella enriched in patients, Eubacterium and Roseburia enriched in controls

- Genera of Clostridiales, Clostridium and Peptostreptococcus negatively correlated with hSCRP

- Atherosclerosis associated with the Ruminococcus enterotype

Quantitative metagenomics · T2D associated with moderate dysbiosis with a decline in butyrate-producing bacteria

- Gut-microbiome-based T2D index accurately classifies T2D individuals

Quantitative metagenomics • Low bacterial richness associates with and 16S rRNA increased overall adiposity, insulin resistance, dyslipidemia, and a more pronounced inflammatory phenotype

- Discrimination between high versus low gene count and obesity status possible from a combination of only four species with ROC analysis AUC of 0.97

- Increased weight gain in individuals with low microbial gene count

Quantitative metagenomics • Increased abundance of Lactobacillus spp. and abundance of Clostridium spp. decreased

- Clostridium spp. correlated with fasting glucose and HbA1c, whereas Lactobacillus spp. correlated negatively with fasting glucose, insulin, C-peptide and TAG, and positively with adiponectin and HDL 
Kong et al. (2013) [160] To investigate the impact of RYGB on microbiota composition

To investigate the impact of RYGB on microbiota composition and function
121 adults; 44 NGT, 64 IGT, Cross-sectional $13 \mathrm{~T} 2 \mathrm{D}$

30 adults; 7 T2D, 23 non-T2D Non-randomized obese

Non-randomize
intervention

6 adults; 5 T2D, 1 non-T2D obese
Non-randomized intervention

- Microbiota composition as determined by metagenomic clusters better correlated with T2D than known clinical risk factors (WC, WHR and BMI)

- Higher abundance of Clostridia in T2D - Negative trend of abundance of Streptococcus from NGT to IGT to T2D

- Enterotype classification not associated with glucose tolerance status

- 28 OTUs associated with glucose tolerance status

- Fasting glucose associated with microbiota composition

- Fasting insulin inversely associated with alpha (intraindividual) diversity

- Increased bacterial richness following RYGB, mainly within the phylum

Proteobacteria

- RYGB induced genus-level changes in microbiota composition correlated with changes in white adipose tissue gene expression

Quantitative metagenomics - Relative abundance of 22 species an 11 genera affected 3 months after RYGB - Overall, RYGB induced phylum-level changes characterized by reduction in Bacteroidetes and Firmicutes and an increase in Proteobacteria and Verrucomicrobia

- Species-level changes dominated by an increase in A. muciniphila, E. coli and K. pneumonia and a decrease in F. prausnitzii, E. rectale and D. invisus.

Abbreviations: $A U C$ area under the curve, $B M I$ body mass index $C V D$ cardiovascular disease, $D Z$ dizygotic, $H D L$ high-density lipoprotein , hsCRP high-sensitivity C-reactive protein, IGT impaired glucose tolerance, $M Z$ monozygotic, $N G T$ normal glucose tolerance, OGTT oral glucose tolerance test, OTU operational taxonomic unit, qPCR quantitative PCR, ROC receiver operating characteristic, RYGB Roux-en-Y gastric bypass, TAG triacylglyceride, T2D type 2 diabetes, WC waist circumference, WHR waist-hip ratio. 
individuals [50], strengthening the gut microbiota as a potential risk factor in the pathogenesis of obesity and its co-morbidities. Here, we look at the main cardiometabolic traits and their associations with gut microbiota composition.

\section{Obesity}

Evidence from several studies in humans and rodents points to the gut microbiota as a contributing factor in obesity development. Studies of the gut microbiota in mice genetically predisposed to obesity $(o b / o b)$ have shown a decreased Bacteroidetes-to-Firmicutes ratio [39], which is associated with an increased capacity for energy harvest from otherwise indigestible dietary polysaccharides [51]. Studies of germ-free mice have demonstrated that they are leaner and more resistant to diet-induced obesity when introduced to a high-fat western-style diet than their conventional counterparts $[52,53]$. After colonizing germ-free mice with microbiota from normal mice, the amount of body fat increased and the insulin sensitivity decreased [52]. Similarly, when colonizing germ-free mice with fecal microbiota from human twin pairs discordant for obesity, mice receiving microbiota from the obese twin showed more weight gain and adiposity than those receiving microbiota from the lean sibling, hinting at a causal effect for the transplanted microbial community [54]. Although inconsistent findings at the phylum level have been reported in human obesity, reduced bacterial diversity has been associated with adiposity [37]. In the Metagenomics of the Human Intestinal Tract (MetaHIT) study including 292 non-diabetic Danish individuals, 23\% of the studied population sample had low microbial gene richness, with the bacterial gene count reduced by $40 \%$ [55]. Interestingly, individuals with low richness were characterized by low-grade inflammation, insulin resistance, dyslipidemia and overall adiposity, which potentially put them at an increased risk of progression to obesity-related comorbidities.

\section{Type 2 diabetes}

It has been reported that patients with T2D have a different taxonomic composition and functional potential of their gut microbiome from that of non-diabetic individuals [12-17]. One recent $16 \mathrm{~S}$ rRNA-based study observed a positive correlation between fecal bifidobacteria and plasma insulin and insulin resistance [56], in disagreement with the previously detected inverse relationship found in mice [57] and humans [58]. A metagenomics-based study including 344 Chinese individuals identified a moderate degree of gut bacterial dysbiosis, with a decline in butyrate-producing bacteria and an increase in opportunistic bacteria among T2D patients [13]. However, no difference in diversity between
T2D patients and healthy controls was observed. A study of 145 Swedish women with normal, impaired or diabetic glucose regulation found comparable, but not identical, compositional changes associated with $\mathrm{T} 2 \mathrm{D}$, suggesting ethnic or regional influences [16]. In both the Swedish and the Chinese study, it was possible to discriminate with high accuracy between T2D patients and nondiabetic controls with few metagenomic markers $[13,16]$. Despite minor discrepancies between individual studies, evidence is mounting that T2D is associated with both functional and compositional changes of the gut microbiota. However, it remains to be firmly established whether these changes are causal or secondary to physiological changes or perhaps pharmacologically induced.

\section{Atherosclerosis and cardiovascular disease}

Thus far, evidence directly linking specific changes in the human gut microbiota with CVD has been limited to a few smaller cross-sectional studies. Although failing to show any overall structural difference between cases and controls on either the phylum or the genus level, a study of 15 patients with clinical atherosclerosis and an equal number of healthy controls matched for sex and age showed several shared operational taxonomic units (OTUs) between atherosclerotic plaques and fecal samples, suggesting that plaque microbiota may at least partially be of intestinal origin [59]. Further analyses using whole-genome sequencing showed that the genus Collinsella was enriched in fecal samples from patients with atherosclerosis, whereas Roseburia and Eubacterium were enriched in healthy controls [60]. In the same study, Clostridiales genera Clostridium and Peptostreptococcus were negatively correlated with high-sensitivity C-reactive protein, an inflammatory marker strongly associated with increased risk of CVD [61].

\section{Mechanisms of microbiota-host interactions}

Although convincing evidence suggests that a dysbiotic state of the gut microbiota composition is associated with metabolic disease, we are still far from fully understanding the complexities of the multiple underlying mechanisms, as outlined below and summarized in Figure 2.

Studies of mice provide early evidence that the gut microbiota has an essential role in energy harvest, in that germ-free mice need to consume approximately $30 \%$ more calories to sustain a body weight similar to conventionally raised mice [52]. An essential mechanism by which the gut microbiota enhances energy harvest is through the hydrolysis and fermentation of otherwise indigestible dietary polysaccharides. Microbial fermentation generates monosaccharides and short chain fatty acids (SCFAs), which can be absorbed and used as energy by the host [62]. Of the three main SCFAs, 


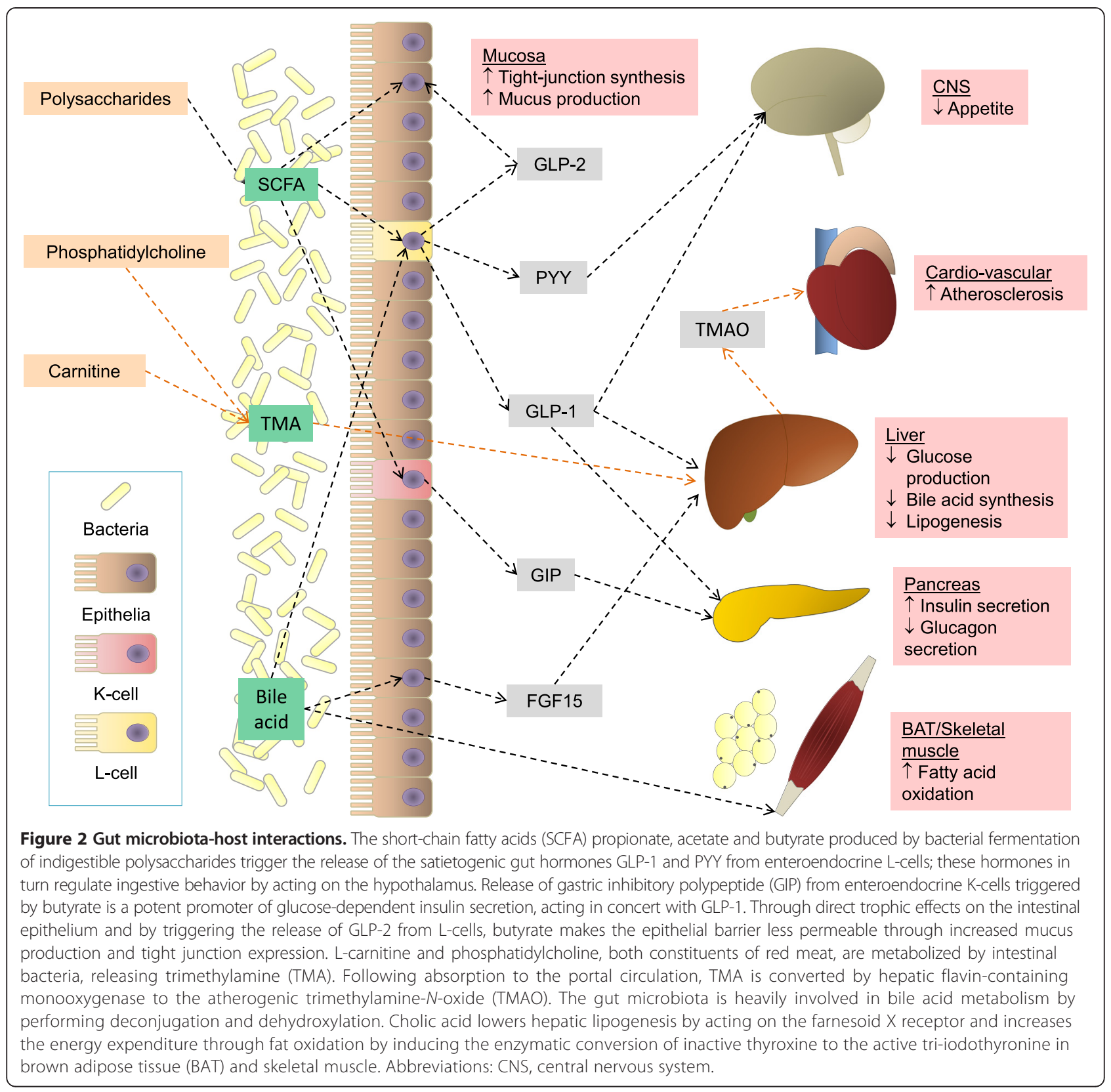

propionate, acetate and butyrate, the latter in particular has attracted attention as a potential mediator of the metabolic effects of dysbiosis (reviewed by Brahe et al. [63]), with several studies in humans demonstrating a reduced proportion of butyrate-producing Clostridiales in T2D and CVD $[13,16,60]$. Butyrate acts by diverse molecular mechanisms to regulate energy intake, expenditure and storage $[64,65]$. It stimulates the release of the satietogenic hormones glucagon-like peptide 1 (GLP-1) and peptide YY (PYY) from enteroendocrine L-cells, at least in part by acting as an agonist for the free fatty acid receptors 2 and 3 (FFAR2/3) [66], thus regulating the ingestive behavior of the host. Similarly, by stimulating the release of gastric inhibitory polypeptide (GIP) from enteroendocrine $\mathrm{K}$-cells it potentially increases host insulin sensitivity in concert with GLP-1 [67]. Butyrate also strengthens the integrity of the intestinal epithelial barrier through effects on mucus production [68] and tight junction expression [69], as well as conferring trophic effects on the epithelial cells, possibly mediated by an incretin hormone, glucagon-like peptide 2 (GLP-2) [70]. The overall effect of this is a reduced passage of toxic and pro-inflammatory substances across the epithelial barrier. Interestingly, the presence of bacteria and 
bacterial residues such as lipopolysaccharide in host blood and other tissues is linked to low grade inflammation, obesity and T2D [71-74], emphasizing the importance of a sustained intestinal barrier in relation to metabolic disorders.

Another way that the gut microbiota influences the metabolic state of the host is through an extensive involvement in bile acid homeostasis [75]. Direct evidence from rodent studies shows that treatment with broadspectrum antibiotics (for example, ampicillin) increases bile acid reabsorption through increased expression of the transporter SLC10A2 [76], while simultaneously increasing hepatic bile acid synthesis by suppressing the expression of fibroblast growth factor 15 [77]. These findings provide clues to the molecular mechanisms underlying the decades-old findings that germ-free animals have substantially higher bile acid concentration in bile [78] along with decreased bile acid excretion in feces [79]. A more recent study gives further weight to the importance of the gut microbiota in bile acid homeostasis; this [80] showed that the mouse gut microbiota regulates expression of cholesterol 7-alpha hydroxylase, the rate-limiting enzyme in bile acid synthesis, through deconjugation of tauro-conjugated muricholic acid, a potent antagonist of the farnesoid X receptor (FXR). Acting on the same receptor, cholic acid reduces circulating triglyceride levels by decreasing the hepatic expression of the SREBP-1c transcription factor controlling genes involved in lipogenesis [81]. Interestingly, FXR deficiency has been reported to improve glucose homeostasis in obese mice [82]. In another study in mice, supplementation with cholic acid protected against and even reversed diet-induced obesity; the effect was mediated by increased expression of the type 2 iodothyronine deiodinase (D2) enzyme and thus increased conversion of inactive thyroxine (T4) to the active tri-iodothyronine (T3) in brown adipose tissue, effectively raising energy expenditure through fat oxidation [83]. Similar effects, regulated by the cAMP-protein kinase A pathway by activation of the G-protein-coupled receptor TGR5, were demonstrated in human skeletal muscle in vitro [83]. Stimulation of the TGR 5 signaling pathway by bile acids has also been demonstrated to induce GLP-1 release from enteroendocrine L-cells and consequently improve glycemic regulation in obese mice [84]. These discoveries have spurred an interest in bile acids as potential therapeutic targets in metabolic disorders. Interestingly, colestimide, a bile acid sequestrant, decreases body weight and improves glucose tolerance and insulin sensitivity in diet-induced obese mice [85], and it improves glycemic regulation and reduces central adiposity in T2D humans and mice $[86,87]$.

Although the evidence for an association between gut microbiota and CVD at the compositional level is scarce, at the functional level metabolism of specific dietary components by the gut microbiota, particularly trimethylamine-containing compounds such as phosphatidylcholine (PC) and carnitine, has been linked to development of CVD. PC- and carnitine-rich foods include red meats, fish, poultry, dairy products and eggs [88,89]. Following ingestion both compounds are metabolized by the gut microbiota to trimethylamine (in the case of carnitine, with $\gamma$-butyrobetaine as an intermediary metabolite), which then enters the circulation and is converted by hepatic flavin-containing monooxygenase to trimethylamine$N$-oxide (TMAO) [90,91]. Studies have shown that TMAO was undetectable in germ-free mice following a carnitine or choline challenge, but following colonization of the animals with microbiota from conventional mice, they gained the ability to produce TMAO $[92,93]$. Furthermore, antibiotic treatment in conventional mice reduced TMAO production after a choline or carnitine challenge $[92,93]$, with similar effects reported in humans $[93,94]$. Mice genetically deficient in phosphatidylethanolamine- $N$ methyltransferase, an enzyme involved in hepatic PC synthesis, are protected from developing atherosclerosis [95], whereas dietary supplementation with either carnitine, $\gamma$-butyrobetaine, choline or TMAO increases atherosclerotic plaque formation in mice genetically susceptible to atherosclerosis [91-93]. In addition, diet-induced TMAO production and atherosclerosis susceptibility is transmissible through microbiota transplantation [96]. It is thus well established that the gut microbiota is intrinsically involved in TMAO production and that TMAO, rather than its precursors choline and carnitine, is the pro-atherogenic compound.

Although the way in which TMAO promotes the formation of atherosclerotic plaques is not entirely clear, several contributing mechanisms have been identified. TMAO has been show to inhibit reverse cholesterol transport by reducing the expression of the hepatic enzymes Cyp7a1 and Cyp27a1, as well as multiple bile acid transporters, while simultaneously inhibiting the expression of intestinal bile acid transporters Npc1L1 and Abcg5/8, thus reducing bile acid synthesis and excretion by the liver and bile acid uptake in the intestine [93]. In macrophages TMAO increases the efflux of cholesterol through increased expression of the cholesterol transporters Abca1 and Abcg1 while simultaneously increasing expression of the proatherogenic scavenger receptors, CD36 and scavenger receptor $A$ [92,93]. In recent years several human clinical studies have demonstrated a clear association between trimethylaminecontaining compounds and CVD risk (Table S1 in Additional file 1). Plasma choline level is a strong predictor of major cardiac events in patients with suspected acute coronary syndrome [97], as well as in individuals with stable coronary artery disease; interestingly, in the 
latter disease it is a predictor only when there are concomitant increased TMAO levels [98]. Similarly, carnitine is an independent predictor of prevalent CVD and incident major cardiac events, but only with concurrent high TMAO levels [93]. TMAO in itself is also an independent predictor of incident death, myocardial infarction and stroke, as well as prevalent CVD even in individuals at low risk of cardiovascular events [94]. Interestingly, elevated TMAO levels have also been reported in patients with T2D [99], chronic kidney disease $[100]$ and heart failure $[99,101]$, disorders that are known to be associated with an increased risk of CVD.

\section{Modulation of the gut microbiota for prevention and therapy}

With the establishment of the gut microbiota as an environmental factor contributing to the development of cardio-metabolic disorders, interest in modulating the microbiota composition and function as a therapeutic strategy is increasing. Theoretically, mechanisms through which modulation of the gut microbiota might be achieved include lifestyle changes, such as dietary intervention or exercise, surgery or the use of pharmaceuticals, or through transplantation from healthy donors.

\section{Diet}

Variation in diet composition is a major contributing factor in determining microbiota diversity. Studies comparing the diversity and phylogenetic composition of gut microbiota from individuals consuming a western-type diet (rich in fat and animal protein) and indigenous people from Africa and South America (living on a diet dominated by plant-based polysaccharides) have demonstrated that the former is associated with an increase in the abundance of Bacteroides spp., whereas the latter is associated with increased Prevotella spp. and overall diversity $[38,102]$. At the phylum level, studies of the effect of high-fat diet in murine models have shown a decrease in the ratio of Bacteroidetes to Firmicutes [103-106], although human studies have not been equally consistent $[11,41,107]$. It is clear, however, that composition and functional capabilities of the human gut microbiota rapidly adapt to changes in macronutrient content of the diet [9-11], mirroring studies in mice that have demonstrated that dietary changes result in an adaptation of the gut microbiota within a few days $[104,105,108]$. Still, compositional changes following dietary intervention are subtle and readily reversible $[109,110]$, and although there are indications that a permanent change in diet could lead to persistent effects on the structure of the gut microbiota [48], the long-term effect of dietary intervention in humans needs to be investigated further. However, recent studies in humans and rodents have demonstrated a remarkable ability of the metabolic capacity of the gut microbiota to be altered by long-term dietary patterns [91,93], indicating that the potential benefits of dietary intervention on host metabolism might very well be significant.

\section{Prebiotics}

The term prebiotics refers to dietary components (mainly non-digestible oligosaccharides) that selectively stimulate the growth or activity of a limited number of microbial genera or species [111]. Studies have consistently shown that the gut microbiota can be modulated by administration of inulin-type fructans and galactans, with a preferential effect on Bifidobacteria and to some extent Lactobacillus spp. (reviewed by Meyer and Stasse-Wolthuis [112]). In a series of studies in rodents and humans, prebiotics acting through changes in microbiota composition have been shown to reduce energy intake and body weight $[113,114]$, concomitantly reducing insulin resistance and hyperglycemia [115-117]. These effects appear to be mediated by increased release of the anorexigenic gut hormones GLP-1, GLP-2 and PYY $[70,113,114,116,118]$, by reduced release of the orexigenic peptide ghrelin [114,118-120], and by reducing endotoxemia by way of improved mucosal barrier function, thus reducing levels of inflammatory markers [57,117,121-123]. Directly affecting the production of SCFAs (butyrate) is another potential mechanism by which prebiotics might beneficially influence host physiology [124-126].

\section{Probiotics}

Probiotics are live microorganisms that, when ingested in sufficient amounts, exert beneficial health effects on the host. The majority of known bacterial probiotics belong to the Gram-positive genera of Lactobacillus and Bifidobacterium, with the Nissle 1917 strain of E. coli being the only extensively investigated Gram-negative probiotic. The therapeutic effects of probiotics in metabolic disorders have been heavily investigated for the past decade, with promising results, although mainly in murine models. Several studies in such models of obesity and diabetes have demonstrated an improved metabolic profile (including but not limited to reduced levels of glucose, insulin, HbA1c, LDL-cholesterol, triglyceride and leptin) following administration of different strains of lactobacilli and bifidobacteria [127-137]. Although human trials have been less consistent (Table S2 in Additional file 1), the majority of studies show a beneficial metabolic effect of probiotics, with only a few smaller studies failing to show an improvement in cardio-metabolic variables.

Increasing knowledge about microbiota-host interactions of specific bacterial species and their metabolites has sparked an interest in so-called next-generation 
probiotics: the use of live genetically modified bacteria to deliver therapeutic molecules to the gut for further processing by the commensal bacterial flora or direct absorption by the host. In a recent study, Chen et al. [138] demonstrated that administering E. coli genetically modified to produce $\mathrm{N}$-acyl-phosphatidylethanolamines (NAPE), the precursors for the potent anorexigenic $\mathrm{N}$-acylethanolamides (NAE), to high-fat fed obese mice for a total of 8 weeks resulted in reduced weight gain and adiposity, without any difference in lean body mass from controls. These effects on body composition endured for 4 weeks after cessation of bacterial administration, and even after 12 weeks the treated mice weighed significantly less. Treated mice also had a more favorable metabolic profile, with lower levels of circulating leptin and insulin, and improved glucose tolerance and insulin sensitivity, along with reduced hepatic steatosis and inflammation. Although treated mice had markedly lower food intake and higher energy expenditure, the latter as a consequence of increased basic metabolic rate, the results indicated a direct effect of NAE at the transcriptional level, with increased expression of genes involved in fatty acid oxidation. Clinical trials of recombinant bacteria in relation to cardio-metabolic disorders have yet to be performed, but the feasibility in humans has been demonstrated in patients with inflammatory bowel disease [139].

\section{Physical activity}

Decreased levels of physical activity is a well-established factor contributing to the global obesity epidemic [140]. Evidence for the existence of a modulating effect of physical activity on the gut microbiota is accumulating, although mainly from rodent models. Physical activity has been shown to affect gut microbiota composition and diversity in healthy rats $[141,142]$, as well as in murine models of obesity [143,144] and hypertension [144], with some results indicating that the demonstrated effects are independent of diet $[143,145]$. So far, studies in humans are few and limited in design, with only one smaller study showing increased diversity and structural changes on the family and genus level in athletes [146]. It is, however, unclear to what extent these changes are attributable to concomitant dietary differences rather than physical activity alone, and future studies are needed to discriminate between these effects and to clarify potential mediating factors.

\section{Antibiotics}

Administration of antimicrobial agents, including broadspectrum antibiotics, has been proposed as a possible contributor to the obesity epidemic and the shrinking gut microbiome richness in the western world. This theory is supported by a few, but large epidemiological studies showing that intake of antibiotics in infancy increases the risk of being overweight at 7 years of age $[147,148]$, and a recent study has shown that even prenatal exposure to antibiotics increases the risk of childhood obesity [149], perhaps through an effect on the maternal gut microbiota. Interestingly, although the risk of being overweight in children of mothers with normal pre-pregnancy body mass index (BMI) is increased by antibiotic treatment early in life, the opposite appears to be the case for children of overweight and obese mothers, for whom the risk is reduced [147]. In addition, non-randomized intervention studies have shown an increase in BMI in adults following antibiotic treatment, especially after Helicobacter pylori eradication in patients with gastric ulcer $[150,151]$. Increased content of SCFA and lower caloric output have been found in feces of mice treated with antibiotics, despite similar caloric intake as the non-treated mice [152], which support previous suggestions of an increased energy harvest leading to obesity [51]. In contrast to these findings, other mouse studies have shown improved glucose tolerance that was independent of weight changes, and also lower levels of circulating lipopolysaccharide and a lower bacterial count following antibiotic treatment, all indications of an improved metabolic state [153,154]. Recently it has been demonstrated that treatment of infant mice with antibiotics in subtherapeutic dosage increases adiposity, even later in life, and confers substantial compositional changes in the microbiota, which when transplanted to germ-free animals induces adiposity [152,155]. In humans, treatment with vancomycin has been shown to reduce peripheral insulin sensitivity in individuals with metabolic syndrome, whereas treatment with amoxicillin does not, reflecting the preferential targeting of Grampositive butyrate-producing bacteria by the former [156]. Although current studies indicate that antibiotics have not only short- but also long-term effects [157] on the diversity and/or configuration of the gut microbiota, the possible role of antibiotics in development of human metabolic diseases needs further exploration.

\section{Bariatric surgery}

Surgical weight-loss intervention, generally referred to as bariatric surgery, is currently the most effective treatment for morbid obesity. In addition to inducing and sustaining a substantial weight loss it is well established that bariatric surgery improves pancreatic beta-cell function through enhanced GLP-1 secretion, enhances insulin sensitivity, promptly ameliorates $\mathrm{T} 2 \mathrm{D}$ and improves cardiovascular risk factors, thereby reducing mortality [158]. Recent studies suggest that the more long-term health benefits of bariatric surgery may in part be due to alterations in the gut microbiota. In non-obese rats, Roux-en-Y gastric bypass (RYGB) confers a dramatic shift in microbiota composition, with a 52-fold increase 
in Proteobacteria and reduction of Firmicutes and Bacteroidetes. These effects in rodents occur within 1 week of surgery and are apparently independent of the induced weight change and caloric restriction [159]. Studies in humans showing similar changes on the phylum level $[14,160,161]$ in addition to increased overall richness substantiate the potent effect of surgery on the microbiota configuration. Studies showing correlation between specific bacterial genera and species (such as Faecalibacterium prausnitzii) and metabolic and inflammatory variables $[14,15]$, as well as change in white adipose tissue gene expression [160], point to the potential role of microbiota as a mediator of the beneficial metabolic effects of bariatric surgery. Transmissibility of reduced adiposity through transplantation of gut microbiota from RYGB mice to germ-free mice further substantiates a potential causative effect [159].

\section{Transplantation - evidence of causality?}

Spurred on by the safe and highly efficacious application of fecal microbiota transplantation in the treatment of recurrent $C$. difficile enterocolitis [162,163], transplantation of fecal matter has gained interest as a potential modulator of cardio-metabolic disorders. In a study of human twins discordant for obesity, colonization of germ-free mice with fecal microbiota from an obese donor induced weight gain, whereas stools from a lean twin did not [54]. Also, cohousing of coprophagic mice inoculated with either obese or lean microbiota protected the recipients of the former from developing the concurrent obese phenotype, although only when the mice were fed a high-fiber low-fat diet and not when fed high-fat, low-fiber diet [54]. A human study investigating 18 insulin resistant men who were randomized to duodenal infusion of either autologous fecal microbiota or microbiota from a heterologous lean donor showed improvement in insulin sensitivity 6 weeks after infusion of microbiota from lean donors (but not of autologous microbiota), along with increased microbiota diversity and an increase in butyrate-producing bacteria [164]. Recently it has been demonstrated that knock-out of MyD88, an adaptor molecule for Toll-like receptors, in mouse intestinal epithelial cells protects the animal from developing obesity and diabetes when fed a high fat diet, and knocking out the gene in obese animals induces weight loss [165].

Interestingly, transplanting gut microbiota from MyD88 knock-out mice fed a high-fat diet reduced weight gain and fat mass development in germ-free recipients fed a similarly high-fat diet. So even though data on any long-term effects are still needed, these pioneering studies in humans and rodents suggest that once a phenotype-specific gut microbiota is established in a given species, the phenotype in question can be transferred to another individual or species susceptible to the pathogenic impact of the given microbiota community.

\section{Concluding remarks}

Although there is convincing evidence that dysbiotic states correlate with cardio-metabolic disorders, the underlying mechanisms have generally not been elucidated in depth. To exploit these and their potentially causal links to the cardiovascular health spectrum, future studies will probably concentrate on functional and mechanistic studies of potentially pathogenic gut microbiota in animal and cellular models, complemented by prospective observational and intervention studies of cardio-metabolic cases that are initially treatment-naïve to avoid confounding by various drugs. Much interest will be given to integrating gut microbiomics discoveries with findings from other pertinent high-throughput techniques such as genomics, epigenomics, metabolomics, lipidomics and peptidomics (of the host) and polymorphism metagenomics, meta-transcriptomics and meta-proteomics (of the microbiota).

Based on current knowledge, as discussed in this review, we hypothesize firstly that certain endogenous or exogenous stimuli (perhaps food, stress or infections) trigger a subclinical gut mucosal inflammation, which, depending on the genetic susceptibility of an individual, favor growth and expansion of a community of specific disease-promoting gut bacteria. Secondly, specific disease-promoting microbiota can be transmitted from an affected donor to a genetically susceptible recipient, where they reproduce the disease phenotype. Finally, it may be a general phenomenon in many disorders, including cardio-metabolic diseases, that once a specific pathological microbiota had developed it constitutes a self-perpetuating pathogenic risk factor. Although ground-breaking research in recent years has enormously expanded our understanding of the microbiota-host interplay, the numerous cellular and molecular mechanisms involved in the pathophysiological interactions await further discovery and characterization.

\section{Additional file}

Additional file 1: Table S1. Human clinical studies of

trimethylamine-containing compounds in relation to cardio-metabolic disorders. Table S2 in Additional file 1: Human clinical trials of probiotic supplements in relation to cardio-metabolic traits.

\section{Abbreviations}

BMI: Body mass index; CVD: Cardiovascular diseases; GLP: Glucagon-like peptide; OTU: Operational taxonomic unit; PC: Phosphatidylcholine; PYY: Peptide YY; RYGB: Roux-en-Y gastric bypass; SCFA: Short chain fatty acids; T2D: Type 2 diabetes; TMAO: Trimethylamine- $N$-oxide.

Competing interests

The authors declare that they have no competing interests. 


\section{Authors' contributions}

All authors were responsible for the conception and design of the manuscript. THH and RJG did the first drafting of the paper. All authors revised and approved the version to be published.

\section{Author details}

${ }^{1}$ The Novo Nordisk Foundation Center for Basic Metabolic Research, Section of Metabolic Genetics, Faculty of Health and Medical Sciences, University of Copenhagen, Universitetsparken 1, København $\varnothing 2100$, Denmark. ${ }^{2}$ Faculty of Health Sciences, University of Southern Denmark, J.B. Winsløws Vej 19-3, Odense C 5000, Denmark.

\section{Published online: 31 March 2015}

\section{References}

1. Caballero B. The global epidemic of obesity: an overview. Epidemiol Rev. 2007:29:1-5

2. Flegal KM, Carroll MD, Ogden $C L$, Curtin LR. Prevalence and trends in obesity among US adults, 1999-2008. JAMA. 2010;303:235-41.

3. McCarthy MI. Genomics, type 2 diabetes, and obesity. N Engl J Med. 2010:363:2339-50

4. Matheus AS, Tannus LR, Cobas RA, Palma CC, Negrato CA, Gomes MB. Impact of diabetes on cardiovascular disease: an update. Int J Hypertens. 2013;2013:653789.

5. Jumpertz R, Le DS, Turnbaugh PJ, Trinidad C, Bogardus C, Gordon Jl, et al. Energy-balance studies reveal associations between gut microbes, caloric load, and nutrient absorption in humans. Am J Clin Nutr. 2011;94:58-65.

6. Purchiaroni F, Tortora A, Gabrielli M, Bertucci F, Gigante G, laniro G, et al. The role of intestinal microbiota and the immune system. Eur Rev Med Pharmacol Sci. 2013;17:323-33.

7. Round JL, Mazmanian SK. The gut microbiota shapes intestinal immune responses during health and disease. Nat Rev Immunol. 2009:9:313-23.

8. Walter J, Ley R. The human gut microbiome: ecology and recent evolutionary changes. Annu Rev Microbiol. 2011;65:411-29.

9. Cotillard A, Kennedy SP, Kong LC, Prifti E, Pons N, Le Chatelier E, et al. Dietary intervention impact on gut microbial gene richness. Nature. 2013:500:585-8.

10. David LA, Maurice CF, Carmody RN, Gootenberg DB, Button JE, Wolfe BE, et al. Diet rapidly and reproducibly alters the human gut microbiome. Nature. 2014;505:559-63.

11. Duncan SH, Belenguer A, Holtrop G, Johnstone AM, Flint HJ, Lobley GE. Reduced dietary intake of carbohydrates by obese subjects results in decreased concentrations of butyrate and butyrate-producing bacteria in feces. Appl Environ Microbiol. 2007:73:1073-8.

12. Larsen N, Vogensen FK, van den Berg FW, Nielsen DS, Andreasen AS, Pedersen BK, et al. Gut microbiota in human adults with type 2 diabetes differs from non-diabetic adults. PLoS One. 2010;5:e9085.

13. Qin J, Li Y, Cai Z, Li S, Zhu J, Zhang F, et al. A metagenome-wide association study of gut microbiota in type 2 diabetes. Nature. 2012:490:55-60.

14. Graessler J, Qin Y, Zhong H, Zhang J, Licinio J, Wong ML, et al. Metagenomic sequencing of the human gut microbiome before and after bariatric surgery in obese patients with type 2 diabetes: correlation with inflammatory and metabolic parameters. Pharmacogenomics J. 2013;13:514-22.

15. Furet JP, Kong LC, Tap J, Poitou C, Basdevant A, Bouillot JL, et al. Differential adaptation of human gut microbiota to bariatric surgery-induced weight loss: links with metabolic and low-grade inflammation markers. Diabetes. 2010;59:3049-57

16. Karlsson FH, Tremaroli V, Nookaew I, Bergstrom G, Behre CJ, Fagerberg B, et al. Gut metagenome in European women with normal, impaired and diabetic glucose control. Nature. 2013:498:99-103.

17. Zhang X, Shen D, Fang Z, Jie Z, Qiu X, Zhang C, et al. Human gut microbiota changes reveal the progression of glucose intolerance. PLOS One. 2013:8:e71108.

18. Manson JM, Rauch M, Gilmore MS. The commensal microbiology of the gastrointestinal tract. Adv Exp Med Biol. 2008;635:15-28.

19. Simon C, Daniel R. Metagenomic analyses: past and future trends. App Environ Microbiol. 2011;77:1153-61.

20. Kuczynski J, Lauber CL, Walters WA, Parfrey LW, Clemente JC, Gevers D, et al. Experimental and analytical tools for studying the human microbiome. Nat Rev Genet. 2012;13:47-58.
21. Weinstock GM. Genomic approaches to studying the human microbiota. Nature. 2012:489:250-6.

22. Rajilic-Stojanovic M, Heilig HG, Molenaar D, Kajander K, Surakka A, Smidt H, et al. Development and application of the human intestinal tract chip, a phylogenetic microarray: analysis of universally conserved phylotypes in the abundant microbiota of young and elderly adults. Environ Microbiol. 2009;11:1736-51.

23. Cole JR, Wang Q, Fish JA, Chai B, McGarrell DM, Sun Y, et al. Ribosomal Database Project: data and tools for high throughput rRNA analysis. Nucleic Acids Res. 2014;42:D633-42.

24. Qin J, Li R, Raes J, Arumugam M, Burgdorf KS, Manichanh C, et al. A human gut microbial gene catalogue established by metagenomic sequencing. Nature. 2010;464:59-65.

25. Nielsen HB, Almeida M, Juncker AS, Rasmussen S, Li J, Sunagawa S, et al. Identification and assembly of genomes and genetic elements in complex metagenomic samples without using reference genomes. Nat Biotechnol. 2014;32:822-8.

26. Li J, Jia H, Cai X, Zhong H, Feng Q, Sunagawa S, et al. An integrated catalog of reference genes in the human gut microbiome. Nat Biotechnol. 2014;32:834-41.

27. Jiménez E, Marín ML, Martín R, Odriozola JM, Olivares M, Xaus J, et al. Is meconium from healthy newborns actually sterile? Res Microbiol. 2008:159:187-93

28. Mshvildadze M, Neu J, Shuster J, Theriaque D, Li N, Mai V. Intestinal microbial ecology in premature infants assessed with non-culture-based techniques. J Pediatr. 2010;156:20-5.

29. Penders J, Thijs C, Vink C, Stelma FF, Snijders B, Kummeling I, et al. Factors influencing the composition of the intestinal microbiota in early infancy. Pediatrics. 2006:118:511-21.

30. Biasucci G, Benenati B, Morelli L, Bessi E, Boehm G. Cesarean delivery may affect the early biodiversity of intestinal bacteria. J Nutr. 2008:138:1796S-800S.

31. Salminen S, Gibson GR, McCartney AL, Isolauri E. Influence of mode of delivery on gut microbiota composition in seven year old children. Gut. 2004;53:1388-9.

32. Jakobsson HE, Abrahamsson TR, Jenmalm MC, Harris K, Quince C, Jernberg $C$, et al. Decreased gut microbiota diversity, delayed Bacteroidetes colonisation and reduced Th1 responses in infants delivered by Caesarean section. Gut. 2014;63:559-66.

33. Thavagnanam S, Fleming J, Bromley A, Shields MD, Cardwell CR. A metaanalysis of the association between Caesarean section and childhood asthma. Clin Exp Allergy. 2008;38:629-33.

34. Li HT, Zhou YB, Liu JM. The impact of Cesarean section on offspring overweight and obesity: a systematic review and meta-analysis. Int J Obes (Lond). 2013;37:893-9.

35. Mshvildadze M, Neu J, Mai V. Intestinal microbiota development in the premature neonate: establishment of a lasting commensal relationship? Nutr Rev. 2008;66:658-63.

36. Bergstrom A, Skov TH, Bahl MI, Roager HM, Christensen LB, Ejlerskov KT, et al. Establishment of intestinal microbiota during early life: a longitudinal, explorative study of a large cohort of Danish infants. Appl Environ Microbiol. 2014;80:2889-900.

37. Turnbaugh PJ, Hamady M, Yatsunenko T, Cantarel BL, Duncan A, Ley RE, et al. A core gut microbiome in obese and lean twins. Nature. 2009;457:480-4

38. Yatsunenko T, Rey FE, Manary MJ, Trehan I, Dominguez-Bello MG, Contreras $\mathrm{M}$, et al. Human gut microbiome viewed across age and geography. Nature. 2012:486:222-7.

39. Ley RE, Bäckhed F, Turnbaugh P, Lozupone CA, Knight RD, Gordon Jl. Obesity alters gut microbial ecology. Proc Natl Acad Sci U S A. 2005;102:11070-5.

40. Ley RE, Knight R, Gordon Jl. The human microbiome: eliminating the biomedical/environmental dichotomy in microbial ecology. Environ Microbiol. 2007;9:3-4.

41. Ley RE, Turnbaugh PJ, Klein S, Gordon Jl. Microbial ecology: human gut microbes associated with obesity. Nature. 2006;444:1022-3.

42. Kashyap PC, Marcobal A, Ursell LK, Smits SA, Sonnenburg ED, Costello EK et al. Genetically dictated change in host mucus carbohydrate landscape exerts a diet-dependent effect on the gut microbiota. Proc Natl Acad Sci U S A. 2013;110:17059-64

43. Benson AK, Kelly SA, Legge R, Ma F, Low SJ, Kim J, et al. Individuality in gut microbiota composition is a complex polygenic trait shaped by multiple 
environmental and host genetic factors. Proc Natl Acad Sci U S A. 2010;107:18933-8.

44. Structure, function and diversity of the healthy human microbiome. Nature. 2012;486:207-14

45. Costello EK, Lauber CL, Hamady M, Fierer N, Gordon Jl, Knight R. Bacteria community variation in human body habitats across space and time. Science. 2009;326:1694-7.

46. Dethlefsen L, Relman DA. Incomplete recovery and individualized responses of the human distal gut microbiota to repeated antibiotic perturbation. Proc Natl Acad Sci U S A. 2011;108:4554-61.

47. Faith JJ, Guruge JL, Charbonneau M, Subramanian S, Seedorf H, Goodman $\mathrm{AL}$, et al. The long-term stability of the human gut microbiota. Science. 2013;341:1237439.

48. Claesson MJ, Jeffery IB, Conde S, Power SE, O'Connor EM, Cusack S, et al. Gut microbiota composition correlates with diet and health in the elderly. Nature. 2012;488:178-84.

49. World Health Organization. Global status report on noncommunicable diseases. World Health Organization. 2014. http://www.who.int/nmh/ publications/ncd-status-report-2014/en/. Accessed 7 February 2015.

50. Cani PD, Delzenne NM. Gut microflora as a target for energy and metabolic homeostasis. Curr Opin Clin Nutr Metab Care. 2007;10:729-34.

51. Turnbaugh PJ, Ley RE, Mahowald MA, Magrini V, Mardis ER, Gordon JI. An obesity-associated gut microbiome with increased capacity for energy harvest. Nature. 2006;444:1027-31.

52. Bäckhed F, Ding H, Wang T, Hooper LV, Koh GY, Nagy A, et al. The gut microbiota as an environmental factor that regulates fat storage. Proc Natl Acad Sci U S A. 2004;101:15718-23.

53. Rabot S, Membrez M, Bruneau A, Gerard P, Harach T, Moser M, et al. Germ-free C57BL/6 J mice are resistant to high-fat-diet-induced insulin resistance and have altered cholesterol metabolism. FASEB J. 2010;24:4948-59.

54. Ridaura VK, Faith JJ, Rey FE, Cheng J, Duncan AE, Kau AL, et al. Gut microbiota from twins discordant for obesity modulate metabolism in mice. Science. 2013;341:1241214.

55. Le Chatelier E, Nielsen T, Qin J, Prifti E, Hildebrand F, Falony G, et al. Richness of human gut microbiome correlates with metabolic markers. Nature. 2013;500:541-6.

56. Salonen A, Lahti L, Salojarvi J, Holtrop G, Korpela K, Duncan SH, et al. Impact of diet and individual variation on intestinal microbiota composition and fermentation products in obese men. ISME J. 2014;8:2218-30.

57. Cani PD, Neyrinck AM, Fava F, Knauf C, Burcelin RG, Tuohy KM, et al. Selective increases of bifidobacteria in gut microflora improve highfat-diet-induced diabetes in mice through a mechanism associated with endotoxaemia. Diabetologia. 2007:50:2374-83.

58. FS Teixeira T, Grzeskowiak LM, Salminen S, Laitinen K, Bressan J, Gouveia Peluzio Mdo C. Faecal levels of Bifidobacterium and Clostridium coccoides but not plasma lipopolysaccharide are inversely related to insulin and HOMA index in women. Clin Nutr. 2013;32:1017-22.

59. Koren O, Spor A, Felin J, Fåk F, Stombaugh J, Tremaroli V, et al. Human oral, gut, and plaque microbiota in patients with atherosclerosis. Proc Natl Acad Sci U S A. 2011;108:4592-8.

60. Karlsson FH, Fåk F, Nookaew I, Tremaroli V, Fagerberg B, Petranovic D, et al. Symptomatic atherosclerosis is associated with an altered gut metagenome. Nat Commun. 2012;3:1245.

61. Greenland P, Alpert JS, Beller GA, Benjamin EJ, Budoff MJ, Fayad ZA, et al. 2010 ACCF/AHA guideline for assessment of cardiovascular risk in asymptomatic adults: A report of the American College of Cardiology Foundation/American Heart Association Task Force on Practice Guidelines. J Am Coll Cardiol. 2010;56:e50-e103.

62. Topping DL, Clifton PM. Short-chain fatty acids and human colonic function: roles of resistant starch and nonstarch polysaccharides. Physiol Rev. 2001;81:1031-64

63. Brahe LK, Astrup A, Larsen LH. Is butyrate the link between diet, intestinal microbiota and obesity-related metabolic diseases? Obesity Rev. 2013;14:950-9.

64. Kimura I, Ozawa K, Inoue D, Imamura T, Kimura K, Maeda T, et al. The gut microbiota suppresses insulin-mediated fat accumulation via the short-chain fatty acid receptor GPR43. Nat Commun. 2013;4:1829.

65. Gao Z, Yin J, Zhang J, Ward RE, Martin RJ, Lefevre M, et al. Butyrate improves insulin sensitivity and increases energy expenditure in mice. Diabetes. 2009;58:1509-17.
66. Tolhurst G, Heffron H, Lam YS, Parker HE, Habib AM, Diakogiannaki E, et al. Short-chain fatty acids stimulate glucagon-like peptide-1 secretion via the G-protein-coupled receptor FFAR2. Diabetes. 2012;61:364-71.

67. Lin HV, Frassetto A, Kowalik Jr EJ, Nawrocki AR, Lu MM, Kosinski JR, et al. Butyrate and propionate protect against diet-induced obesity and regulate gut hormones via free fatty acid receptor 3 -independent mechanisms. PLoS One. 2012;7:e35240.

68. Willemsen LE, Koetsier MA, van Deventer SJ, van Tol EA. Short chain fatty acids stimulate epithelial mucin 2 expression through differential effects on prostaglandin $\mathrm{E}(1)$ and $\mathrm{E}(2)$ production by intestinal myofibroblasts. Gut. 2003;52:1442-7.

69. Wang HB, Wang PY, Wang X, Wan YL, Liu YC. Butyrate enhances intestinal epithelial barrier function via up-regulation of tight junction protein Claudin-1 transcription. Dig Dis Sci. 2012;57:3126-35.

70. Cani PD, Possemiers S, Van de Wiele T, Guiot Y, Everard A, Rottier O, et al. Changes in gut microbiota control inflammation in obese mice through a mechanism involving GLP-2-driven improvement of gut permeability. Gut. 2009;58:1091-103.

71. Erridge C, Attina T, Spickett CM, Webb DJ. A high-fat meal induces lowgrade endotoxemia: evidence of a novel mechanism of postprandial inflammation. Am J Clin Nutr. 2007;86:1286-92.

72. Creely SJ, McTernan PG, Kusminski CM. Fisher f M, Da Silva NF, Khanolkar M, et al. Lipopolysaccharide activates an innate immune system response in human adipose tissue in obesity and type 2 diabetes. Am J Physiol Endocrinol Metab. 2007:292:E740-7.

73. Amar J, Serino M, Lange C, Chabo C, lacovoni J, Mondot S, et al. Involvement of tissue bacteria in the onset of diabetes in humans: evidence for a concept. Diabetologia. 2011;54:3055-61.

74. Pussinen PJ, Havulinna AS, Lehto M, Sundvall J, Salomaa V. Endotoxemia is associated with an increased risk of incident diabetes. Diabetes Care. 2011;34:392-7.

75. Ridlon JM, Kang DJ, Hylemon PB. Bile salt biotransformations by human intestinal bacteria. J Lipid Res. 2006;47:241-59.

76. Miyata M, Yamakawa H, Hamatsu M, Kuribayashi H, Takamatsu Y, Yamazoe Y. Enterobacteria modulate intestinal bile acid transport and homeostasis through apical sodium-dependent bile acid transporter (SLC10A2) expression. J Pharmacol Exp Ther. 2011;336:188-96.

77. Miyata M, Takamatsu Y, Kuribayashi H, Yamazoe Y. Administration of ampicillin elevates hepatic primary bile acid synthesis through suppression of ileal fibroblast growth factor 15 expression. J Pharmacol Exp Ther. 2009:331:1079-85.

78. Wostmann BS. Intestinal bile acids and cholesterol absorption in the germfree rat. J Nutr. 1973;103:982-90.

79. Madsen D, Beaver M, Chang L, Bruckner-Kardoss E, Wostmann B. Analysis of bile acids in conventional and germfree rats. J Lipid Res. 1976;17:107-11.

80. Sayin Sama I, Wahlström A, Felin J, Jäntti S, Marschall H-U, Bamberg K, et al. Gut microbiota regulates bile acid metabolism by reducing the levels of tauro-beta-muricholic acid, a naturally occurring FXR antagonist. Cell Metab. 2013;17:225-35.

81. Watanabe M, Houten SM, Wang L, Moschetta A, Mangelsdorf DJ, Heyman RA, et al. Bile acids lower triglyceride levels via a pathway involving FXR, SHP, and SREBP-1C. J Clin Invest. 2004;113:1408-18.

82. Prawitt J, Abdelkarim M, Stroeve JHM, Popescu I, Duez H, Velagapudi VR, et al. Farnesoid $X$ receptor deficiency improves glucose homeostasis in mouse models of obesity. Diabetes. 2011;60:1861-71.

83. Watanabe M, Houten SM, Mataki C, Christoffolete MA, Kim BW, Sato H, et al. Bile acids induce energy expenditure by promoting intracellular thyroid hormone activation. Nature. 2006:439:484-9.

84. Thomas C, Gioiello A, Noriega L, Strehle A, Oury J, Rizzo G, et al. TGR5mediated bile acid sensing controls glucose homeostasis. Cell Metab. 2009;10:167-77.

85. Watanabe M, Morimoto K, Houten SM, Kaneko-Iwasaki N, Sugizaki T, Horai Y, et al. Bile acid binding resin improves metabolic control through the induction of energy expenditure. PLOS One. 2012;7:e38286.

86. Suzuki T, Oba K, Igari Y, Watanabe K, Matsumura N, Futami-Suda S, et al. Effects of bile-acid-binding resin (colestimide) on blood glucose and visceral fat in Japanese patients with type 2 diabetes mellitus and hypercholesterolemia: an open-label, randomized, case-control, crossover study. J Diabetes Complications. 2012;26:34-9.

87. Kobayashi M, Ikegami H, Fujisawa T, Nojima K, Kawabata Y, Noso S, et al. Prevention and treatment of obesity, insulin resistance, and diabetes by bile acid-binding resin. Diabetes. 2007;56:239-47. 
88. Steiber A, Kerner J, Hoppel CL. Carnitine: a nutritional, biosynthetic, and functional perspective. Mol Aspects Med. 2004;25:455-73.

89. Zeisel SH, Mar MH, Howe JC, Holden JM. Concentrations of cholinecontaining compounds and betaine in common foods. J Nutr. 2003;133:1302-7.

90. Bennett BJ, de Aguiar Vallim TQ, Wang Z, Shih DM, Meng Y, Gregory J, et al. Trimethylamine-N-oxide, a metabolite associated with atherosclerosis, exhibits complex genetic and dietary regulation. Cell Metab. 2013;17:49-60.

91. Koeth RA, Levison BS, Culley MK, Buffa JA, Wang Z, Gregory JC, et al. Gamma-butyrobetaine is a proatherogenic intermediate in gut microbial metabolism of L-carnitine to TMAO. Cell Metab. 2014;20:799-812.

92. Wang Z, Klipfell E, Bennett BJ, Koeth R, Levison BS, DuGar B, et al. Gut flora metabolism of phosphatidylcholine promotes cardiovascular disease. Nature. 2011:472:57-63.

93. Koeth RA, Wang Z, Levison BS, Buffa JA, Org E, Sheehy BT, et al. Intestinal microbiota metabolism of I-carnitine, a nutrient in red meat, promotes atherosclerosis. Nat Med. 2013;19:576-85.

94. Tang WHW, Wang Z, Levison BS, Koeth RA, Britt EB, Fu X, et al. Intestinal microbial metabolism of phosphatidylcholine and cardiovascular Risk. N Engl J Med. 2013;368:1575-84.

95. Cole LK, Dolinsky WW, Dyck JR, Vance DE. Impaired phosphatidylcholine biosynthesis reduces atherosclerosis and prevents lipotoxic cardiac dysfunction in ApoE-/- mice. Circ Res. 2011;108:686-94.

96. Gregory JC, Buffa JA, Org E, Wang Z, Levison BS, Zhu W, et al. Transmission of atherosclerosis susceptibility with gut microbial transplantation. J Biol Chem. 2014. doi:10.1074/jbc.M114.618249.

97. Danne O, Lueders C, Storm C, Frei U, Möckel M. Whole blood choline and plasma choline in acute coronary syndromes: Prognostic and pathophysiological implications. Clin Chim Acta. 2007;383:103-9.

98. Wang Z, Tang WHW, Buffa JA, Fu X, Britt EB, Koeth RA, et al. Prognostic value of choline and betaine depends on intestinal microbiota-generated metabolite trimethylamine-N-oxide. Eur Heart J. 2014;35:904-10.

99. Tang WHW, Wang Z, Shrestha K, Borowski AG, Wu Y, Troughton RW, et al. Intestinal microbiota-dependent phosphatidylcholine metabolites, diastolic dysfunction, and adverse clinical outcomes in chronic systolic heart failure. J Card Fail. 2015;21:91-6.

100. Tang WH, Wang Z, Kennedy DJ, Wu Y, Buffa JA, Agatisa-Boyle B, et al. Gut microbiota-dependent trimethylamine $\mathrm{N}$-oxide (TMAO) pathway contributes to both development of renal insufficiency and mortality risk in chronic kidney disease. Circ Res. 2015;116:448-55.

101. Tang WHW, Wang Z, Fan Y, Levison B, Hazen JE, Donahue LM, et al. Prognostic value of elevated levels of intestinal microbe-generated metabolite trimethylamine- $\mathrm{N}$-oxide in patients with heart failure: refining the gut hypothesis. J Am Coll Cardiol. 2014;64:1908-14.

102. De Filippo C, Cavalieri D, Di Paola M, Ramazzotti M, Poullet JB, Massart S, et al. Impact of diet in shaping gut microbiota revealed by a comparative study in children from Europe and rural Africa. Proc Natl Acad Sci U S A. 2010;107:14691-6.

103. Turnbaugh PJ, Backhed F, Fulton L, Gordon Jl. Diet-induced obesity is linked to marked but reversible alterations in the mouse distal gut microbiome. Cell Host Microbe. 2008;3:213-23.

104. Turnbaugh PJ, Ridaura VK, Faith JJ, Rey FE, Knight R, Gordon J. The effect of diet on the human gut microbiome: a metagenomic analysis in humanized gnotobiotic mice. Sci Transl Med. 2009;1:6ra14.

105. Hildebrandt MA, Hoffmann C, Sherrill-Mix SA, Keilbaugh SA, Hamady M, Chen $Y Y$, et al. High-fat diet determines the composition of the murine gut microbiome independently of obesity. Gastroenterology. 2009;137:1716-24.

106. Murphy E, Cotter P, Healy S, Marques T, O'Sullivan O, Fouhy F, et al. Composition and energy harvesting capacity of the gut microbiota: relationship to diet, obesity and time in mouse models. Gut. 2010;59:1635-42.

107. Arumugam M, Raes J, Pelletier E, Le Paslier D, Yamada T, Mende DR, et al. Enterotypes of the human gut microbiome. Nature. 2011;473:174-80.

108. de Wit N, Derrien M, Bosch-Vermeulen H, Oosterink E, Keshtkar S, Duval C, et al. Saturated fat stimulates obesity and hepatic steatosis and affects gut microbiota composition by an enhanced overflow of dietary fat to the distal intestine. Am J Physiol Gastrointest Liver Physiol. 2012:303:G589-99.

109. Wu GD, Chen J, Hoffmann C, Bittinger K, Chen Y-Y, Keilbaugh SA, et al. Linking long-term dietary patterns with gut microbial enterotypes. Science. 2011;334:105-8.
110. Walker AW, Ince J, Duncan SH, Webster LM, Holtrop G, Ze X, et al. Dominant and diet-responsive groups of bacteria within the human colonic microbiota. ISME J. 2011;5:220-30

111. Roberfroid M. Prebiotics: the concept revisited. J Nutr. 2007;137:830S-7S.

112. Meyer D, Stasse-Wolthuis M. The bifidogenic effect of inulin and oligofructose and its consequences for gut health. Eur J Clin Nutr. 2009;63:1277-89.

113. Cani PD, Lecourt E, Dewulf EM, Sohet FM, Pachikian BD, Naslain D, et al. Gut microbiota fermentation of prebiotics increases satietogenic and incretin gut peptide production with consequences for appetite sensation and glucose response after a meal. Am J Clin Nutr. 2009;90:1236-43.

114. Parnell JA, Reimer RA. Weight loss during oligofructose supplementation is associated with decreased ghrelin and increased peptide $Y Y$ in overweight and obese adults. Am J Clin Nutr. 2009;89:1751-9.

115. Sasaki M, Ogasawara N, Funaki Y, Mizuno M, lida A, Goto C, et al. Transglucosidase improves the gut microbiota profile of type 2 diabetes mellitus patients: a randomized double-blind, placebo-controlled study. BMC Gastroenterol. 2013;13:81.

116. Everard A, Lazarevic V, Derrien M, Girard M, Muccioli GG, Neyrinck AM, et al. Responses of gut microbiota and glucose and lipid metabolism to prebiotics in genetic obese and diet-induced leptin-resistant mice. Diabetes. 2011:60:2775-86.

117. Neyrinck AM, Possemiers S, Druart C, Van de Wiele T, De Backer F, Cani PD, et al. Prebiotic effects of wheat arabinoxylan related to the increase in bifidobacteria, Roseburia and Bacteroides/Prevotella in diet-induced obese mice. PLoS One. 2011;6:e20944.

118. Parnell JA, Reimer RA. Prebiotic fibres dose-dependently increase satiety hormones and alter Bacteroidetes and Firmicutes in lean and obese JCR:LA-cp rats. Br J Nutr. 2012;107:601-13.

119. Cani PD, Dewever C, Delzenne NM. Inulin-type fructans modulate gastrointestinal peptides involved in appetite regulation (glucagon-like peptide-1 and ghrelin) in rats. Br J Nutr. 2004;92:521-6.

120. Cani PD, Neyrinck AM, Maton N, Delzenne NM. Oligofructose promotes satiety in rats fed a high-fat diet: involvement of glucagon-like peptide-1. Obes Res. 2005;13:1000-7.

121. Cani PD, Bibiloni R, Knauf C, Waget A, Neyrinck AM, Delzenne NM, et al. Changes in gut microbiota control metabolic endotoxemia-induced inflammation in high-fat diet-induced obesity and diabetes in mice. Diabetes. 2008;57:1470-81.

122. Neyrinck AM, Van Hee VF, Piront N, De Backer F, Toussaint O, Cani PD, et al. Wheat-derived arabinoxylan oligosaccharides with prebiotic effect increase satietogenic gut peptides and reduce metabolic endotoxemia in dietinduced obese mice. Nutr Diabetes. 2012;2:e28.

123. Everard A, Belzer C, Geurts L, Ouwerkerk JP, Druart C, Bindels LB, et al. Crosstalk between Akkermansia muciniphila and intestinal epithelium controls diet-induced obesity. Proc Natl Acad Sci U S A. 2013;110:9066-71.

124. Morrison DJ, Mackay WG, Edwards CA, Preston T, Dodson B, Weaver LT. Butyrate production from oligofructose fermentation by the human faecal flora: what is the contribution of extracellular acetate and lactate? $\mathrm{Br} J$ Nutr. 2006:96:570-7.

125. Scott KP, Martin JC, Duncan SH, Flint HJ. Prebiotic stimulation of human colonic butyrate-producing bacteria and bifidobacteria, in vitro. FEMS Microbiol Ecol. 2014;87:30-40.

126. Kleessen B, Hartmann L, Blaut M. Oligofructose and long-chain inulin: influence on the gut microbial ecology of rats associated with a human faecal flora. Br J Nutr. 2001;86:291-300.

127. Hsieh FC, Lee CL, Chai CY, Chen WT, Lu YC, Wu CS. Oral administration of Lactobacillus reuteri GMNL-263 improves insulin resistance and ameliorates hepatic steatosis in high fructose-fed rats. Nutr Metab (Lond). 2013;10:35.

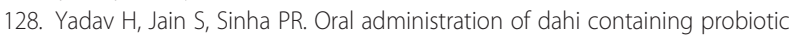
Lactobacillus acidophilus and Lactobacillus casei delayed the progression of streptozotocin-induced diabetes in rats. J Dairy Res. 2008;75:189-95.

129. Park JE, Oh SH, Cha YS. Lactobacillus plantarum LG42 isolated from gajami sik-hae decreases body and fat pad weights in diet-induced obese mice. J Appl Microbiol. 2014;116:145-56.

130. Sakai T, Taki T, Nakamoto A, Shuto E, Tsutsumi R, Toshimitsu T, et al. Lactobacillus plantarum OLL2712 regulates glucose metabolism in C57BL/6 mice fed a high-fat diet. J Nutr Sci Vitaminol (Tokyo). 2013;59:144-7.

131. Bejar W, Hamden K, Ben Salah R, Chouayekh H. Lactobacillus plantarum TN627 significantly reduces complications of alloxan-induced diabetes in rats. Anaerobe. 2013;24:4-11. 
132. Kang JH, Yun SI, Park MH, Park JH, Jeong SY, Park HO. Anti-obesity effect of Lactobacillus gasseri BNR17 in high-sucrose diet-induced obese mice. PLoS One. 2013;8:e54617.

133. Kang J, Yun S, Park H. Effects of Lactobacillus gasseri BNR17 on body weight and adipose tissue mass in diet-induced overweight rats. J Microbiol. 2010;48:712-14.

134. Kim SW, Park KY, Kim B, Kim E, Hyun CK. Lactobacillus rhamnosus GG improves insulin sensitivity and reduces adiposity in high-fat diet-fed mice through enhancement of adiponectin production. Biochem Biophys Res Commun. 2013:431:258-63.

135. Zhang Y, Wang L, Zhang J, Li Y, He Q, Li H, et al. Probiotic Lactobacillus casei Zhang ameliorates high-fructose-induced impaired glucose tolerance in hyperinsulinemia rats. Eur J Nutr. 2014;53:221-32.

136. Plaza-Diaz J, Gomez-Llorente C, Abadia-Molina F, Saez-Lara MJ, Campana-Martin L, Munoz-Quezada S, et al. Effects of Lactobacillus paracasei CNCM I-4034, Bifidobacterium breve CNCM I-4035 and Lactobacillus rhamnosus CNCM I-4036 on hepatic steatosis in Zucker rats. PLoS One. 2014;9:e98401.

137. Reichold A, Brenner SA, Spruss A, Forster-Fromme K, Bergheim I, Bischoff SC. Bifidobacterium adolescentis protects from the development of nonalcoholic steatohepatitis in a mouse model. J Nutr Biochem. 2014;25:118-25.

138. Chen Z, Guo L, Zhang Y, Walzem RL, Pendergast JS, Printz RL, et al. Incorporation of therapeutically modified bacteria into gut microbiota inhibits obesity. J Clin Invest. 2014;124:3391-406.

139. Braat H, Rottiers P, Hommes D, Huyghebaert N, Remaut E, Remon J, et al. A phase I trial with transgenic bacteria expressing interleukin-10 in Crohn's disease. Clin Gastroenterol Hepatol. 2006;4:754-9.

140. Obesity: preventing and managing the global epidemic. Report of a WHO consultation. World Health Organ Tech Rep Ser. 2000;894:1-253.

141. Queipo-Ortuno M, Seoane L, Murri M, Pardo M, Gomez-Zumaquero J, Cardona F, et al. Gut microbiota composition in male rat models under different nutritional status and physical activity and its association with serum leptin and ghrelin levels. PLoS One. 2013:8:e65465.

142. Matsumoto M, Inoue $R$, Tsukahara T, Ushida K, Chiji H, Matsubara N, et al. Voluntary running exercise alters microbiota composition and increases $\mathrm{N}$-butyrate concentration in the rat cecum. Biosci Biotechnol Biochem. 2008;72:572-6.

143. Evans C, LePard K, Kwak J, Stancukas M, Laskowski S, Dougherty J, et al. Exercise prevents weight gain and alters the gut microbiota in a mouse model of high fat diet-induced obesity. PLoS One. 2014;9:e92193.

144. Petriz B, Castro A, Almeida J, Gomes C, Fernandes G, Kruger R, et al. Exercise induction of gut microbiota modifications in obese, non-obese and hypertensive rats. BMC Genomics. 2014;15:511.

145. Kang S, Jeraldo P, Kurti A, Miller ME, Cook M, Whitlock K, et al. Diet and exercise orthogonally alter the gut microbiome and reveal independent associations with anxiety and cognition. Mol Neurodegener. 2014;9:36.

146. Clarke SF, Murphy EF, O'Sullivan O, Lucey AJ, Humphreys M, Hogan A, et al Exercise and associated dietary extremes impact on gut microbial diversity. Gut. 2014:63:1913-20.

147. Ajslev TA, Andersen CS, Gamborg M, Sorensen TI, Jess T. Childhood overweight after establishment of the gut microbiota: the role of delivery mode, pre-pregnancy weight and early administration of antibiotics. Int J Obes (Lond). 2011;35:522-9.

148. Trasande L, Blustein J, Liu M, Corwin E, Cox LM, Blaser MJ. Infant antibiotic exposures and early-life body mass. Int J Obes (Lond). 2013;37:16-23.

149. Mueller NT, Whyatt R, Hoepner L, Oberfield S, Gloria Dominguez-Bello M, Widen EM, et al. Prenatal exposure to antibiotics, cesarean section, and risk of childhood obesity. Int J Obes (Lond). 2014. doi:10.1038/ijo.2014.180.

150. Francois F, Roper J, Joseph N, Pei Z, Chhada A, Shak JR, et al. The effect of $\mathrm{H}$. pylori eradication on meal-associated changes in plasma ghrelin and leptin. BMC Gastroenterol. 2011;11:37

151. Thuny F, Richet H, Casalta JP, Angelakis E, Habib G, Raoult D. Vancomycin treatment of infective endocarditis is linked with recently acquired obesity. PLoS One. 2010;5:e9074.

152. Cho I, Yamanishi S, Cox L, Methe BA, Zavadil J, Li K, et al. Antibiotics in early life alter the murine colonic microbiome and adiposity. Nature. 2012;488:621-6.

153. Carvalho BM, Guadagnini D, Tsukumo DM, Schenka AA, Latuf-Filho P, Vassallo J, et al. Modulation of gut microbiota by antibiotics improves insulin signalling in high-fat fed mice. Diabetologia. 2012;55:2823-34.
154. Membrez M, Blancher F, Jaquet M, Bibiloni R, Cani PD, Burcelin RG, et al. Gut microbiota modulation with norfloxacin and ampicillin enhances glucose tolerance in mice. FASEB J. 2008;22:2416-26.

155. Cox LM, Yamanishi S, Sohn J, Alekseyenko AV, Leung JM, Cho I, et al. Altering the intestinal microbiota during a critical developmental window has lasting metabolic consequences. Cell. 2014;158:705-21.

156. Vrieze A, Out C, Fuentes S, Jonker L, Reuling I, Kootte RS, et al. Impact of oral vancomycin on gut microbiota, bile acid metabolism, and insulin sensitivity. J Hepatol. 2014;60:824-31.

157. Jernberg C, Lofmark S, Edlund C, Jansson JK. Long-term ecological impacts of antibiotic administration on the human intestinal microbiota. ISME J. 2007;1:56-66.

158. Gloy VL, Briel M, Bhatt DL, Kashyap SR, Schauer PR, Mingrone G, et al. Bariatric surgery versus non-surgical treatment for obesity: a systematic review and meta-analysis of randomised controlled trials. BMJ. 2013:347:f5934.

159. Liou AP, Paziuk M, Luevano J-M, Machineni S, Turnbaugh PJ, Kaplan LM. Conserved shifts in the gut microbiota due to gastric bypass reduce host weight and adiposity. Sci Transl Med. 2013;5:178ra141.

160. Kong LC, Tap J, Aron-Wisnewsky J, Pelloux V, Basdevant A, Bouillot JL, et al. Gut microbiota after gastric bypass in human obesity: increased richness and associations of bacterial genera with adipose tissue genes. Am J Clin Nutr. 2013;98:16-24.

161. Zhang H, DiBaise JK, Zuccolo A, Kudrna D, Braidotti M, Yu Y, et al. Human gut microbiota in obesity and after gastric bypass. Proc Natl Acad Sci U S A. 2009;106:2365-70.

162. van Nood E, Vrieze A, Nieuwdorp M, Fuentes S, Zoetendal EG, de Vos WM, et al. Duodenal infusion of donor feces for recurrent Clostridium difficile. New Engl J Med. 2013;368:407-15.

163. Youngster I, Russell GH, Pindar C, Ziv-Baran T, Sauk J, Hohmann EL. Oral, capsulized, frozen fecal microbiota transplantation for relapsing Clostridium difficile infection. JAMA. 2014:312:1772-8.

164. Vrieze A, Van Nood E, Holleman F, Salojarvi J, Kootte RS, Bartelsman JF, et al. Transfer of intestinal microbiota from lean donors increases insulin sensitivity in individuals with metabolic syndrome. Gastroenterology. 2012;143:913-16. e917.

165. Everard A, Geurts L, Caesar R, Van Hul M, Matamoros S, Duparc T, et al. Intestinal epithelial MyD88 is a sensor switching host metabolism towards obesity according to nutritional status. Nat Commun. 2014;5:5648.

166. Thomas T, Gilbert J, Meyer F. Metagenomics - a guide from sampling to data analysis. Microb Inform Exp. 2012;2:3. 